\title{
Ultrasensitive Visual Sensing of Molybdate Based on Enzymatic-like Etching of Gold Nanorods
}

\author{
Zhiyang Zhang, ${ }^{\dagger+}$ Zhaopeng Chen, ${ }^{* \dagger}$ and Lingxin Chen ${ }^{\dagger}$
}

${ }^{\dagger}$ Key Laboratory of Coastal Environmental Processes and Ecological Remediation, and Shandong Provincial Key Laboratory of Coastal Environmental Processes, Yantai Institute of Coastal Zone Research (YIC), Chinese Academy of Sciences (CAS), YICCAS, Yantai Shandong 264003, People's Republic of China

${ }^{\ddagger}$ University of Chinese Academy of Sciences, Beijing 100049, China

\section{Supporting Information}

ABSTRACT: Here, we have developed a novel approach to the visual detection of molybdate with high sensitivity and selectivity in aqueous media based on the combination of catalytic formation of iodine and iodine-mediated etching of gold nanorods. In weak acid solution, like peroxidase, molybdate can catalyze the reaction between $\mathrm{H}_{2} \mathrm{O}_{2}$ and $\mathrm{I}^{-}$to produce $\mathrm{I}_{2}$, a moderate oxidant, which then etches gold nanorods preferentially along the longitudinal direction in the presence of hexadecyltrimethylammonium bromide. The etching results in the longitudinal localized surface plasmon resonance extinction peak shifts to short wavelength, accompanied by a color change from blue to red. Under optimal conditions, this sensor exhibits good sensitivity with a

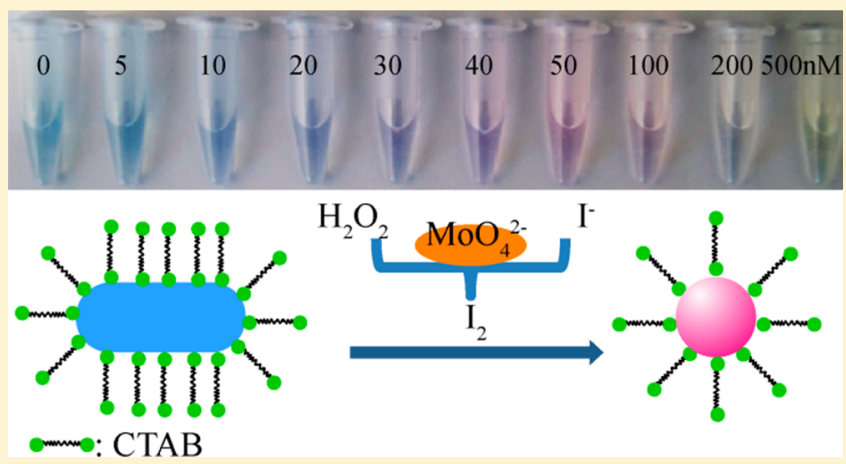
detection limit of $1.0 \mathrm{nM}$. The approach is highlighted by its high selectivity and tolerance to interference, which enables the sensor to detect molybdate directly in real samples, such as tap water, drinking water, and seawater. In addition, perhaps the proposed sensing strategy can be also used for other targets that can selectively regulate the formation of $I_{2}$ under given conditions.

\section{INTRODUCTION}

In recent years, gold nanoparticle-based visual detection methods have attracted considerable attention because of their simplicity, sensitivity, as well as the potential application to on-site detection. ${ }^{1-4}$ Most of these methods are based on the strategy that targets directly or indirectly trigger the aggregation of functionalized gold nanoparticles. The aggregation of gold nanoparticles can lead to a red-shift of the distance-dependent localized surface plasmon resonance (LSPR) absorption of gold nanoparticles, resulting in a visible color change from red to blue. The obvious color change provides a practical platform for colorimetric sensing of various targets, including metal ions, anions, small organic molecules, oligonucleotides, and proteins. However, in most cases, the nanoparticle-aggregation-based methods require complex require tedious and relatively uncontrollable labeling steps to incorporate analyte recognition reagents onto the nanoparticle surface. In addition, almost all of the nanoparticle-aggregation-based visual detection methods suffer from the autoaggregation of nanoparticles in complex samples (e.g., seawater), which often causes high backgrounds and even false positive results. To some degree, the two disadvantages inherently limit the application of these methods.

To avoid the disadvantages in the foregoing paragraph, recently a promising platform based on etching of gold nanoparticles has been developed for visual sensing of some targets, including $\mathrm{Cu}^{2+}, \mathrm{Pb}^{2+}, \mathrm{Fe}^{3+}, \mathrm{Co}^{2+}, \mathrm{Cr}(\mathrm{VI}), \mathrm{CN}^{-}, \mathrm{I}^{-}, \mathrm{Cl}^{-}$, $\mathrm{NO}_{2}{ }^{-}, \mathrm{H}_{2} \mathrm{O}_{2}$, and glucose. ${ }^{5-19}$ The mechanism of this strategy is based on the shape- or size-dependent LSPR absorption of gold nanoparticle. The etching leads to the morphological change of gold nanoparticle, resulting in the change of the LSPR absorption. For this platform, no labeling step and nanoparticles aggregation are required. Thus, this kind of sensor often not only can avoid a tedious procedure to modify nanoparticles but also gets rid of a false positive signal due to the autoaggregation of nanoparticles. Unfortunately, this platform can be only used to sense very limited analytes. To date, these analytes can be divided into three types: (i) analytes $\left(\mathrm{H}_{2} \mathrm{O}_{2}, \mathrm{Cu}^{2+}, \mathrm{Cr}(\mathrm{VI}), \mathrm{I}^{-}, \mathrm{Fe}^{3+} \text {, and } \mathrm{NO}_{2}^{-}\right)^{5-13}$ whose redox potential is higher than that of $\mathrm{Au}(\mathrm{I}) / \mathrm{Au}^{0}$ at certain condition; (ii) analytes $\left(\mathrm{Pb}^{2+}, \mathrm{CN}^{-}\right.$, and $\left.\mathrm{Cl}^{-}\right)$that can reduce the redox potential of $\mathrm{Au}(\mathrm{I}) / \mathrm{Au}^{0}$ by formation of metal-Au alloys or stable gold/analyte complex; ${ }^{14-18}$ and (iii) analyte (glucose and $\mathrm{Co}^{2+}$ ) that can trigger the generation of strong oxidants, ${ }^{5,6,19}$ such as $\mathrm{H}_{2} \mathrm{O}_{2}$, hydroxyl radical $\left({ }^{\bullet} \mathrm{OH}\right)$, and superoxide radical $\left(\mathrm{O}_{2}{ }^{--}\right)$. Therefore, to expand this kind of sensor will be a very interesting and meaningful work.

Received: June 9, 2015

Revised: July 13, 2015

Published: July 30, 2015 
Molybdenum, existing mainly in natural water as molybdate, is an essential trace element for plants and animals, including humans. ${ }^{20,21}$ However, at high concentration, molybdenum can be toxic to humans, plants, and animals. As recommended by the U.S. EPA, the molybdenum in daily drinking water should be less than $50 \mu \mathrm{g} \mathrm{L}^{-1}(255 \mathrm{nM})$ for adults. ${ }^{21}$ Thus, many sensitive methods, including $\mathrm{AAS},{ }^{21,22} \mathrm{ICP}^{\mathrm{MS}},{ }^{23,24}$ spectrophotometry, ${ }^{25-27}$ fluorescence, ${ }^{28}$ voltammetry, ${ }^{29-31}$ and colorimetry, $^{20,32,33}$ have been established for the detection of molybdenum. In general, due to the avoidance of a sophisticated instrument and that the detection signal can be observed by the naked eye, the colorimetric method is more suitable for on-site detection. However, existent visual methods for molybdenum based on the formation of colored organic dye-molybdenum complex or catalytic spectrophotometry often face poor sensitivity. High sensitivity also plays a very significant role in the accuracy of detection. Because the components of most sample matrixes (e.g., seawater) are very complex, they often interfere with the accuracy of detection. So, highly sensitive sensors are often required to allow for sufficient sample dilution and effectively reduce the matrix interference.

Molybdate has a peroxidase-like activity that can catalyze the oxidization of iodide by hydrogen peroxide to produce iodine. Inspired by this, we proposed a nanoparticle-based visual detection method for sensing of molybdate at nanomolar concentrations. The principle for the method is based on that the molybdate accelerates the production of iodine, a moderate oxidant, which can etch cetyltrimethylammonium bromide (CTAB) stabilized gold nanorods (GNRs) along the longitudinal direction. The etching results in a blue-shift of the longitudinal LSPR absorption of GNRs and an obvious color change from pale blue to red, providing a spectrometry or visual method for sensing of molybdate in complex water matrix, such as drinking water, tap water, and seawater. Because of the high molar extinction coefficient of GNRs, the proposed method obtains high sensitivity with a detection limit of 1.0 $\mathrm{nM}$, which is lower than that of almost of all existent visual methods.

\section{EXPERIMENTAL SECTION}

Chemicals and Apparatus. Hydrogen tetrachloroaurate(III) dehydrate, ascorbic acid, cetyltrimethylammonium bromide (CTAB), sodium molybdate $\left(\mathrm{Na}_{2} \mathrm{MoO}_{4}\right), \mathrm{H}_{2} \mathrm{O}_{2}, \mathrm{NaBH}_{4}$, and $\mathrm{AgNO}_{3}$ were obtained from Sinopharm Chemical Reagent (China). All other chemicals were analytical reagent grade or better. Solutions were prepared with deionized water (18.2 $\mathrm{M} \Omega$, Pall Cascada).

Scanning electron microscopy was performed on a Hitachi FE-SEM S-4800 instrument operated at $5.0 \mathrm{kV}$. Absorption (extinction) spectra were measured on a Thermo Scientific NanoDrop 2000/2000C spectrophotometer. ESI-MS were determined on a LCQ Fleet ion trap mass spectrometer (Thermo Fisher Scientific, San Jose, CA).

Preparation of Gold Nanorods. The GNRs were synthesized using a modified method by changing the amount of $\mathrm{AgNO}_{3}{ }^{34}$ (1) Seed Solution: To $7.5 \mathrm{~mL}$ of CTAB $(0.10 \mathrm{M})$ solution were added $0.25 \mathrm{~mL}$ of $\mathrm{HAuCl}_{4} \cdot 3 \mathrm{H}_{2} \mathrm{O}(0.01 \mathrm{M})$ and $0.60 \mathrm{~mL}$ of ice-cold $\mathrm{NaBH}_{4}$ $(0.01 \mathrm{M})$ in sequence. The mixed solution was kept in a $26^{\circ} \mathrm{C}$ water bath for $2 \mathrm{~h}$. (2) Growth Solution: Under stirring, $1.2 \mathrm{~mL}$ of $0.05 \mathrm{M}$ $\mathrm{HAuCl}_{4} \cdot 3 \mathrm{H}_{2} \mathrm{O}, 0.3 \mathrm{~mL}$ of $\mathrm{AgNO}_{3}(0.01 \mathrm{M})$, and $0.96 \mathrm{~mL}$ of ascorbic acid $(0.1 \mathrm{M})$ were added to $100 \mathrm{~mL}$ of CTAB $(0.10 \mathrm{M})$ in sequence. Finally, $0.2 \mathrm{~mL}$ of seed solution prepared in step (1) was added at room temperature. The color of the solution gradually changed to purple within $20 \mathrm{~min}$. The solution was further left for 2 days without stirring. SEM image showed the GNRs with an aspect ratio of 2:1. The colloid was found to be stable for at least 6 months.
Procedure for Certification of Etching Products. The $\mathrm{pH}$ of as-synthesized GNRs $(1000 \mu \mathrm{L})$ was first adjusted to 3.6 by addition acetate buffer solution. Next, $20 \mu \mathrm{L}$ of $\mathrm{H}_{2} \mathrm{O}_{2}(0.1 \mathrm{M}), 5 \mu \mathrm{L}$ of $\mathrm{KI}(0.1$ $\mathrm{M})$, and $10 \mu \mathrm{L}$ of $\mathrm{MoO}_{4}{ }^{2-}(0.1 \mathrm{mM})$ were added into the above solution. The mixture solution was incubated at $50{ }^{\circ} \mathrm{C}$ for $15 \mathrm{~min}$, and the final solution was subjected to measure the extinction spectrum and mass spectra.

Procedure for Detection of Molybdate. The measurement was carried out in $0.2 \mathrm{M}$ acetate buffer solution $(900 \mu \mathrm{L}, \mathrm{pH}$ 3.6) containing different concentrations of $\mathrm{MoO}_{4}{ }^{2-}$. First, $20 \mu \mathrm{L}$ of $\mathrm{H}_{2} \mathrm{O}_{2}$ $(0.01 \mathrm{M})$ and $5 \mu \mathrm{L}$ of $\mathrm{KI}(0.1 \mathrm{M})$ were added into the acetate buffer solution; then $100 \mu \mathrm{L}$ of gold nanorods solution containing $0.1 \mathrm{M}$ $\mathrm{CTAB}$ was added to the mixed solution as the colorimetric indictor. The mixture solution was incubated at $50{ }^{\circ} \mathrm{C}$ for $15 \mathrm{~min}$ and then subjected to record the extinction spectra.

Detection of Molybdate in Real Samples. Different concentrations of molybdate were spiked in drinking water, tap water, and seawater. $100 \mu \mathrm{L}$ was added into $800 \mu \mathrm{L}$ of acetate buffer solution $(\mathrm{pH}$ 3.6, $0.23 \mathrm{M}$ ). A detection procedure similar to that described above was conducted.

\section{RESULTS AND DISCUSSION}

Principle for the Etching of GNRs. Molybdate is a peroxidase-like chemical that can accelerate the reaction between iodide and hydrogen peroxide to produce iodine in acid solution. $^{35,36}$ The produced iodine, a moderate oxidant, can cause the corrosion of CTAB stabilized gold nanorods. Scheme 1 illustrates the sensing mechanism for the detection of

Scheme 1. Schematic Illustration for Visual Detection of Molybdate Based on Catalytic Etching of GNRs

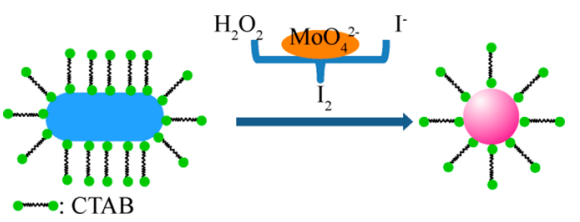

molybdate based on catalytic etching of GNRs. Light blue CTAB-stabilized GNRs with an average aspect ratio of 2:1 (Figure 1A) in acetate buffer ( $\mathrm{pH}$ 3.6) exhibited a strong

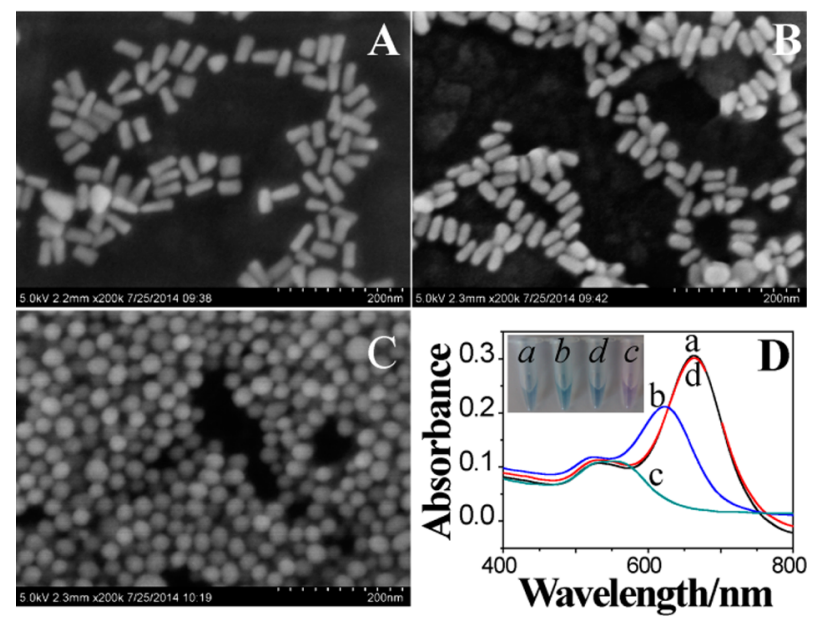

Figure 1. SEM images (A-C), extinction spectra (D), and color ( $a, b$, c) of GNRs before (A, a, $a)$ and after incubation with $0(\mathrm{~B}, \mathrm{~b}, b)$ and $50 \mathrm{nM} \mathrm{MoO}_{4}{ }^{2-}(\mathrm{C}, \mathrm{c}, \mathrm{c})$ in acetate buffer $(\mathrm{pH} 3.6)$ containing $0.5 \mathrm{mM}$ of iodide and $0.2 \mathrm{mM}$ of $\mathrm{H}_{2} \mathrm{O}_{2}$ at $50{ }^{\circ} \mathrm{C}$ for $15 \mathrm{~min}$. Curve $\mathrm{d}$ and digital photo $d$ present the extinction spectrum and color of GNRs in the presence of $\mathrm{MoO}_{4}{ }^{2-}$ only. 
longitudinal LSPR band and a weak transverse LSPR band near 660 and $520 \mathrm{~nm}$, respectively (curve a in Figure 1D). ${ }^{37}$ The addition of iodide $(0.5 \mathrm{mM})$ and hydrogen peroxide $(0.2 \mathrm{mM})$ caused the disappearance of corner angles on the GNRs surface and a blue-shift of the longitudinal LSPR from 660 to $624 \mathrm{~nm}$ after incubation at $50{ }^{\circ} \mathrm{C}$ for $15 \mathrm{~min}$, accompanied by a slight color change (Figure 1B, curves $\mathrm{a}$ and $\mathrm{b}$ and digital photos $a$ and $b$ in Figure 1D). This result means that the GNRs were corroded slowly by hydrogen peroxide in the presence of iodide. It has been reported that $\mathrm{H}_{2} \mathrm{O}_{2}$ can directly etch gold nanorods in the presence of CTAB. ${ }^{38,39}$ Most recently, Ni and co-workers also proposed and certified ${\mathrm{a} \mathrm{Br}_{3}}^{-}$mediated etching of GNRs by $\mathrm{H}_{2} \mathrm{O}_{2}{ }^{40}$ However, in our system, $0.2 \mathrm{mM} \mathrm{H}_{2} \mathrm{O}_{2}$ induced a very tiny change of LSPR of GNRs with the presence of $10 \mathrm{mM} \mathrm{CTAB}$ (Figure S1), which is also consistent with the previous results that $\mathrm{H}_{2} \mathrm{O}_{2}$ below $10 \mathrm{mM}$ led to negligible oxidation of GNRs. ${ }^{40} \mathrm{In}$ addition, the heating effect $\left(50{ }^{\circ} \mathrm{C}\right)$ on the blue shift of LSPR was also excluded because of the ignorable influence on the absorption spectrum of GNRs (Figure S2). So, the corrosion of GNRs was probably caused by the tiny amount of iodine coming from the chemical reaction between hydrogen peroxide and iodide, which was very slow in the absence of appropriate catalyst. The preferential corrosion of the corner angles results from the less surface passivation and/or the higher reaction activities at the tips. ${ }^{39,41}$ With the presence of $50 \mathrm{nM}$ of molybdate, the reaction between hydrogen peroxide and iodide was accelerated and large amounts of iodine were produced, leading to quick etching of GNRs along the longitudinal direction. The etching turned GNRs almost into a sphere and led to a blue shift of the longitudinal LSPR from 624 to $560 \mathrm{~nm}$, accompanied by an obvious color change from light blue to red (Figure 1C, curve $c$ and digital photo $c$ in Figure 1D). It is worth noting here that only molybdate would not etch GNRs without the presence of hydrogen peroxide and iodide (curve $\mathrm{d}$ and digital photo $\mathrm{d}$ in Figure 1D). This phenomenon provides a possibility for the visual detection of molybdate.

To investigate the intrinsic mechanism of the etching GNRs, several control experiments were implemented in the following steps.

Figure S3 shows the UV-vis spectra in acetate buffer solution ( $\mathrm{pH}$ 3.6) containing different chemicals, including $\mathrm{I}^{-}$, $\mathrm{MoO}_{4}{ }^{2-}$, and $\mathrm{H}_{2} \mathrm{O}_{2}$ after incubation at $50{ }^{\circ} \mathrm{C}$ for $15 \mathrm{~min}$. $\mathrm{I}^{-}$and the mixture of $\mathrm{I}^{-}$and $\mathrm{MoO}_{4}{ }^{2-}$ produced no obvious absorption in the range from 300 to $800 \mathrm{~nm}$ (curves $\mathrm{a}$ and $\mathrm{b}$ ). The further addition of $\mathrm{H}_{2} \mathrm{O}_{2}$ to the mixture of $\mathrm{I}^{-}$and $\mathrm{MoO}_{4}{ }^{2-}$ resulted in obvious absorption peaks at 290 and $360 \mathrm{~nm}$ (curve c), indicating large amounts of triiodine $\left(\mathrm{I}_{3}^{-}\right)$were produced after the introduction of $\mathrm{H}_{2} \mathrm{O}_{2}{ }^{42}$ In the absence of $\mathrm{MoO}_{4}{ }^{2-}$, the addition of $\mathrm{H}_{2} \mathrm{O}_{2}$ caused weak absorption at 290 and $360 \mathrm{~nm}$, which meant a tiny amount of $\mathrm{I}_{3}{ }^{-}$was generated (curve $\mathrm{d}$ ). The results were also consistent with the digital photo inset in Figure S3, from which one could see the addition of $\mathrm{H}_{2} \mathrm{O}_{2}$ made the mixture solution of $\mathrm{I}^{-}$and $\mathrm{MoO}_{4}{ }^{2-}$ change from colorless to faint yellow. To further confirm the formation of iodine, we added starch to the solution mentioned above. The solution containing $\mathrm{I}^{-}, \mathrm{MoO}_{4}{ }^{2-}$, and $\mathrm{H}_{2} \mathrm{O}_{2}$ produced strong absorption in the range from 400 to $800 \mathrm{~nm}$ and the solution turned to dark blue (Figure S4), further suggesting large amounts of iodine were produced. It is well-known that peroxidase can catalyze the oxidation of $\mathrm{I}^{-}$by $\mathrm{H}_{2} \mathrm{O}_{2}$. As a comparison, the horseradish peroxidase (HRP) was used to replace $\mathrm{MoO}_{4}{ }^{2-}$ for the parallel experiment. The addition of
HRP also resulted in the formation of iodine (Figures S5 and S6). These results mean that molybdate has a peroxidase-like activity that can accelerate the reaction between iodide and hydrogen peroxide under $\mathrm{pH}$ 3.6.

Now that the presence of $\mathrm{MoO}_{4}{ }^{2-}$ accelerates the formation of iodine, it is necessary to prove that iodine can corrode GNRs in aqueous solution theoretically and experimentally. It was reported that $\mathrm{I}_{3}{ }^{-}$solution is an effective reagent to leach gold from ores. ${ }^{43}$ The leaching of gold in an iodide electrolyte can be discribed as an electrochemical process as follows, where $\phi^{0}$ is the standard reduction potential vs normal hydrogen electrode (NHE):

$$
\begin{aligned}
& \text { anodic: } \mathrm{Au}+2 \mathrm{I}^{-} \rightarrow \mathrm{AuI}_{2}{ }^{-}+\mathrm{e}^{-} \phi_{1}^{0}=0.578 \mathrm{~V} \\
& \text { cathodic: } \mathrm{I}_{3}^{-}+2 \mathrm{e}^{-} \rightarrow 3 \mathrm{I}^{-} \phi_{2}{ }^{0}=0.535 \mathrm{~V}
\end{aligned}
$$

The overall reaction is therefore

$$
\begin{aligned}
& 2 \mathrm{Au}+\mathrm{I}_{3}{ }^{-}+\mathrm{I}^{-} \rightarrow 2 \mathrm{AuI}_{2}{ }^{-} \\
& \Delta \phi=\phi_{2}{ }^{0}-\phi_{1}{ }^{0}+(\mathrm{RT} / 2 \mathrm{~F}) \ln \left\{\left[\mathrm{I}_{3}{ }^{-}\right]\left[\mathrm{I}^{-}\right] /\left[\mathrm{AuI}_{2}{ }^{-}\right]^{2}\right\}
\end{aligned}
$$

According to eq 3 , the $\Delta \phi$ can be controlled by adjusting the concentrations of $\mathrm{I}^{-}, \mathrm{I}_{3}^{-}$, and $\mathrm{AuI}_{2}^{-}$. For example, given the concentrations of $\mathrm{I}^{-}, \mathrm{I}_{3}{ }^{-}$, and $\mathrm{AuI}_{2}{ }^{-}$are $0.5,0.05$, and $0.01 \mathrm{mM}$, respectively, $\Delta \phi$ is calculated to be $0.027 \mathrm{~V}$, indicating reaction 3 can occur spontaneously.

It was also reported that the presence of cetyltrimethylammonium $\left(\mathrm{CTA}^{+}\right)$, a cation with large volume, could reduce the reduction potential of $\mathrm{Au}(\mathrm{I})$ halide/ $\mathrm{Au}$ by formation of ionassociation compound according to soft and hard acid-base theory. For example, the redox potential of $\mathrm{AuBr}_{2}{ }^{-}-(\mathrm{CTA})_{2}{ }^{+} /$ $\mathrm{Au}\left(<0.2 \mathrm{~V}\right.$ vs NHE) is less than that of $\mathrm{AuBr}_{2}{ }^{-} / \mathrm{Au}(0.93 \mathrm{~V}$ vs $\mathrm{NHE}){ }^{44}$ In our experimental system, a large amount of $\mathrm{CTA}^{+}$ also existed. The produced $\mathrm{Au}(\mathrm{I})$ probably existed as $\mathrm{AuBr}_{2}{ }^{-}-$ (CTA $)_{2}^{+}$. According to thermodynamics, if the reaction is fast enough, the reaction extent is controlled by $\Delta \phi\left(\Delta \phi=\phi^{0}\left(\mathrm{I}_{3}{ }^{-} /\right.\right.$ $\left.\mathrm{I}^{-}\right)-\phi^{0}\left(\mathrm{AuBr}_{2}{ }^{-}-\left(\mathrm{CTA}^{+}\right)_{2} / \mathrm{Au}\right)+(\mathrm{RT} / \mathrm{F}) \ln \left\{\left(\left[\mathrm{I}_{3}{ }^{-}\right]\right.\right.$ $\left.\left.\left[\mathrm{CTA}^{+}\right]^{2}\left[\mathrm{Br}^{-}\right]^{2}\right) /\left(\left[\mathrm{AuBr}_{2}{ }^{-}-(\mathrm{CTA})_{2}\right]\left[\mathrm{I}^{-}\right]^{3}\right)\right\}$, where $\phi^{0}\left(\mathrm{I}_{3}^{-} /\right.$ $\left.\mathrm{I}^{-}\right)$and $\phi^{0}\left(\mathrm{AuBr}_{2}^{-}-\left(\mathrm{CTA}^{+}\right)_{2}\right)$ are the standard reduction potentials of $\mathrm{I}_{3}^{-} / \mathrm{I}^{-}$and $\mathrm{AuBr}_{2}{ }^{-}-\left(\mathrm{CTA}^{+}\right)_{2} / \mathrm{Au}$, respectively. The presence of $\mathrm{CTA}^{+}$can increase $\Delta \phi$ significantly and therefore would make the reaction between $\mathrm{I}_{3}{ }^{-}$and gold nanorods more thorough.

To verify the speculation mentioned above experimentally, several control experiments were implemented. Figure 2 shows the extinction spectra of Tween-20 stabilized gold nanoparticles after incubation with different chemicals, including $\mathrm{I}^{-}, \mathrm{I}_{2}$, and $\mathrm{CTAB}$ (note the use of gold nanoparticles avoided the introduction of $\mathrm{CTAB}$ in the synthesis procedure). The Tween-20 stabilized gold nanoparticles exhibited a strong LSPR band around $523 \mathrm{~nm}$ (curve a). The addition of $50 \mu \mathrm{M} \mathrm{I}_{2}$ resulted in a slight decrease of the LSPR adsorption, indicating gold nanoparticles were etched by $\mathrm{I}_{2}$ slightly (curve b). For lack of $\mathrm{I}^{-}$, the formation of insoluble AuI capped on gold nanoparticles and hindered the further oxidation of gold nanoparticles. ${ }^{43}$ In the coexistence of $50 \mu \mathrm{M} \mathrm{I}_{2}$ and $0.5 \mathrm{mM} \mathrm{I}^{-}$, the LSPR band of gold nanoparticles decreases drastically (curve $\mathrm{c}$ ). The result means that the presence of $\mathrm{I}^{-}$promoted the etching of gold nanoparticles due to the formation of soluble $\mathrm{AuI}_{2}{ }^{-}{ }^{43}$ The same result was obtained in the coexistence of $50 \mu \mathrm{M} \mathrm{I}_{2}$ and $10 \mathrm{mM} \mathrm{CTAB} \mathrm{(curve} \mathrm{d).} \mathrm{Curve}$ 


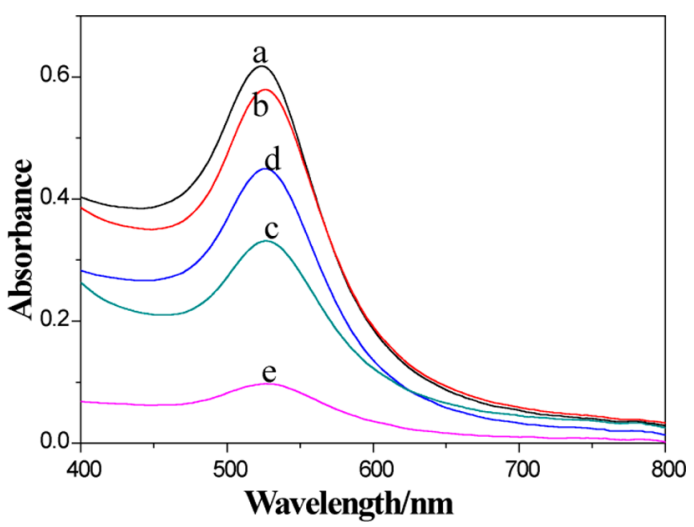

Figure 2. Extinction spectra of Tween-20 stabilized gold nanoparticles (a) and after incubation with $50 \mu \mathrm{M} \mathrm{I}_{2}$ (b), mixture of $50 \mu \mathrm{M} \mathrm{I}_{2}$ and $0.5 \mathrm{mM} \mathrm{I}^{-}$(c), mixture of $50 \mu \mathrm{M} \mathrm{I}_{2}$ and $10 \mathrm{mM} \mathrm{CTAB} \mathrm{(d),} \mathrm{and}$ mixture of $50 \mu \mathrm{M} \mathrm{I}_{2}, 0.5 \mathrm{mM} \mathrm{I}^{-}$, and $10 \mathrm{mM} \mathrm{CTAB} \mathrm{(e)} \mathrm{in} \mathrm{acetate}$ buffer solution $\left(\mathrm{pH} \mathrm{3.6)}\right.$ at $50{ }^{\circ} \mathrm{C}$ for $10 \mathrm{~min}$ The concentration of Tween-20 is $0.6 \%(\mathrm{v} / \mathrm{v})$.

e indicates that $\mathrm{CTA}^{+}$and $\mathrm{I}^{-}$(halide ions) have a synergy effect on the oxidation of gold nanoparticles. The result is also similar to the ethanediamine-thiosulfate system, which was applied to leaching of gold from ores. The positive effect of CTAB on the etching of gold nanoparticles may be due to the formation of ion-association compound between $\mathrm{Au}(\mathrm{I})$ halide and $\mathrm{CTA}^{+}$, which not only reduced the reduction potential of $\mathrm{Au}(\mathrm{I}) / \mathrm{Au}^{44}$ making the reduction of $\mathrm{I}_{3}^{-}$by gold nanorods more thorough, but also eliminated insoluble AuI on gold nanoparticles' surface. $^{45}$

To further prove the gold was oxidized to (I) instead of $\mathrm{Au}(\mathrm{III})$, the etching products were certified by extinction and mass spectra. The extinction spectrum (Figure S7) shows no characteristic absorption peaks for $\mathrm{AuBr}_{4}^{-}(260 \mathrm{~nm}, 390 \mathrm{~nm})^{46}$ and $\mathrm{AuBr}_{4}{ }^{-}-\left(\mathrm{CTA}^{+}\right)_{2}(400 \mathrm{~nm}),{ }^{44,47}$ in the range from 200 to $800 \mathrm{~nm}$, indicating GNRs were probably oxidized to $\mathrm{Au}(\mathrm{I})$. It is also reasonable in theory because $\mathrm{Au}$ (III) cannot coexist with iodide in acidic condition. ${ }^{48}$ The peaks at 290 and $360 \mathrm{~nm}$ are attributed to the production of $\mathrm{I}_{3}{ }^{-42}$ which is consistent to the absorption spectra of $\mathrm{I}_{3}^{-}$in Figure S3. The mass spectrum (Figure 3) indicates several components are present: $\mathrm{CTA}^{+}$at $m / z$ 284.52, $\mathrm{Br}^{-}-\left(\mathrm{CTA}^{+}\right)_{2}$ at $m / z$ 647.26, $\left(\mathrm{Br}^{-}\right)_{2}-\left(\mathrm{CTA}^{+}\right)_{3}$ at $m / z$ 1011.77, $\left(\mathrm{Br}^{-}\right)_{3}-\left(\mathrm{CTA}^{+}\right)_{4}$ at $m / z$ 1376.65, $\left(\mathrm{Br}^{-}\right)_{4}-$

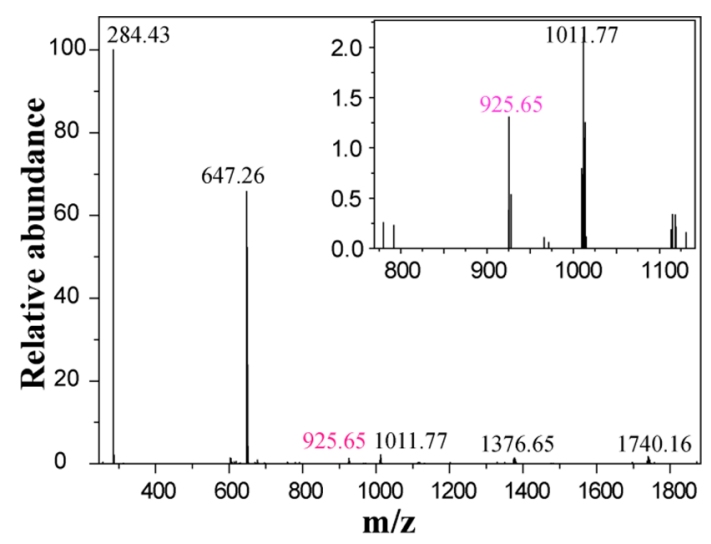

Figure 3. Mass spectrum of as-synthesized GNRs after incubation in mixed solution of $2.0 \mathrm{mM} \mathrm{H}_{2} \mathrm{O}_{2}, 0.5 \mathrm{mM} \mathrm{KI}$, and $1.0 \mu \mathrm{M} \mathrm{MoO}_{4}{ }^{2-}$ (pH 3.6) at $50{ }^{\circ} \mathrm{C}$ for $15 \mathrm{~min}$.
$\left(\mathrm{CTA}^{+}\right)_{5}$ at $m / z$ 1740.16, and the product $\mathrm{AuBr}_{2}{ }^{-}-\left(\mathrm{CTA}^{+}\right)_{2}$ at $m / z$ 925.26. These experimental results demonstrate GNRs were transformed into $\mathrm{Au}(\mathrm{I})$ instead of $\mathrm{Au}(\mathrm{III})$.

On the basis of the above experimental results and our previous work, ${ }^{9}$ we proposed a possible etching reaction described as follows:

$$
\begin{aligned}
& 2 \mathrm{I}^{-}+\mathrm{H}_{2} \mathrm{O}_{2}+2 \mathrm{H}^{+} \stackrel{\mathrm{MoO}_{4}^{2-}}{\longrightarrow} \mathrm{I}_{2}+2 \mathrm{H}_{2} \mathrm{O} \\
& \mathrm{I}_{2}+\mathrm{I}^{-} \rightarrow \mathrm{I}_{3}^{-} \\
& \mathrm{I}_{3}^{-}+2 \mathrm{Au} \rightarrow 2 \mathrm{AuI}+\mathrm{I}^{-} \\
& \mathrm{AuI}+2 \mathrm{Br}^{-} \rightarrow \mathrm{AuBr}_{2}^{-}+\mathrm{I}^{-} \\
& \mathrm{AuBr}_{2}^{-}+2 \mathrm{CTA}^{+} \rightarrow \mathrm{AuBr}_{2}^{-}-\left(\mathrm{CTA}^{+}\right)_{2}
\end{aligned}
$$

Sensitivity and Specificity of the Visual Detection for Molybdate. As mentioned above, the outstanding catalytic property of $\mathrm{MoO}_{4}{ }^{2-}$ on the etching of GNRs possibly provides an approach for sensitive determination of $\mathrm{MoO}_{4}{ }^{2-}$ by naked eye. Figure 4 shows the responses of the nanoparticles-etching-

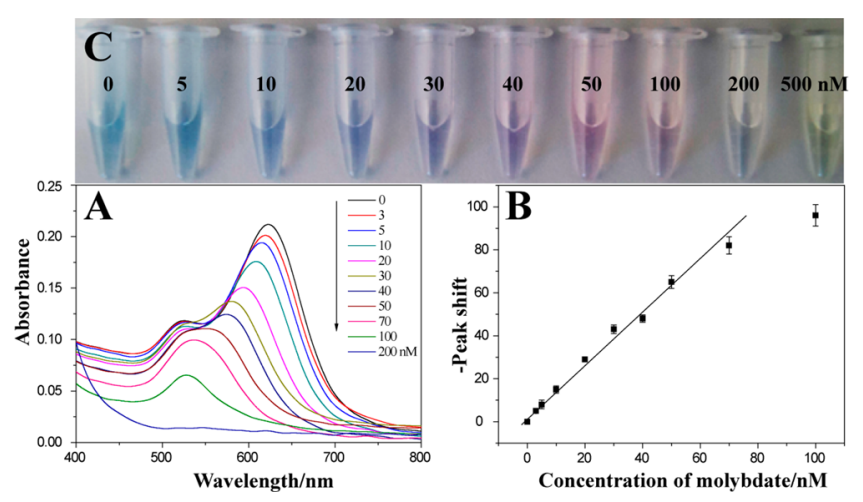

Figure 4. UV extinction spectra (A), LSPR peak shift (B), and color change (C) of GNRs after incubation with different concentrations of $\mathrm{MoO}_{4}{ }^{2-}$ at $50{ }^{\circ} \mathrm{C}$ for $15 \mathrm{~min}$, respectively. Other conditions: $\mathrm{pH}$ 3.6; $\mathrm{I}^{-} 0.5 \mathrm{mM} ; \mathrm{H}_{2} \mathrm{O}_{2} 0.2 \mathrm{mM}$.

based sensor to different concentrations of $\mathrm{MoO}_{4}{ }^{2-}$ under optimal conditions ( $\mathrm{pH} 3.6, \mathrm{KI} 0.5 \mathrm{mM}, \mathrm{H}_{2} \mathrm{O}_{2} 0.2 \mathrm{mM}$, incubation temperature $50{ }^{\circ} \mathrm{C}$, measuring time $15 \mathrm{~min}$, Figures S8-S12). The longitudinal LSPR peak of GNRs shifted to short wavelength gradually with the increase in $\mathrm{MoO}_{4}{ }^{2-}$ concentrations in the range of $0-100 \mathrm{nM}$ (Figure 4A). The LSPR peak of GNRs almost disappeared when the concentration of $\mathrm{MoO}_{4}{ }^{2-}$ increased to $200 \mathrm{nM}$, indicating the GNRs were oxidized completely. In addition, a linear relationship between the peak-shift and $\mathrm{MoO}_{4}{ }^{2-}$ concentrations in the range of 3-70 $\mathrm{nM}$ can be obtained (Figure 4B). The detection limit was calculated to be $1.0 \mathrm{nM}$ according to the $\mathrm{S} / \mathrm{N}=3$ rule, which is lower than that of most visual sensors and is comparable to the results obtained by AAS, ICPMS, spectrophotometry, fluorescence, etc. (Table 1). The digital photo (Figure 4C) shows that the color of GNRs' solutions changed from blue to red with the increase in $\mathrm{MoO}_{4}{ }^{2-}$ concentration. The color change as induced by $10 \mathrm{nM}$ $\mathrm{MoO}_{4}{ }^{2-}$ can be easily observed by the naked eye. To the best of our knowledge, the visual detection limit, $10 \mathrm{nM}$, is among the lowest reported for the detection of molybdenum.

The specificity of the sensor toward $\mathrm{MoO}_{4}{ }^{2-}$ was evaluated by examining the extinction spectra of GNRs in acetate buffer solution in the presence of various other cations and anions, 
Table 1. Comparison of the Performance of Different Analytical Methods for Detection of Molybdenum

\begin{tabular}{|c|c|c|c|c|}
\hline method & technique or material & linear range & LOD & ref \\
\hline AAS & liquid-liquid microextraction/electrothermal AAS & $5-90 \mathrm{nM}$ & $0.21 \mathrm{nM}$ & 21 \\
\hline AAS & liquid-liquid microextraction/graphite furnace AAS & $0.4-8.3 \mathrm{nM}$ & $0.072 \mathrm{nM}$ & 22 \\
\hline ICPMS & chelation ion chromatography/ICPMS & $0.5-1040 \mathrm{nM}$ & $<0.5 \mathrm{nM}$ & 23 \\
\hline ICPMS & ion-exchange chromatography/ICPMS & & $0.01 \mathrm{nM}$ & 24 \\
\hline spectrofluorimetry & anion-exchange resin-spectrofluorimetry & $21-210 \mathrm{nM}$ & & 25 \\
\hline spectrophotometry & integrated microconduit flow injection analysis & $4.2-420 \mu \mathrm{M}$ & $12 \mu \mathrm{M}$ & 26 \\
\hline spectrophotometry & $\mathrm{C}(18) \mathrm{mimBr} /$ pyrogallol red & & $7.7 \mathrm{nM}$ & 27 \\
\hline voltammetry & hanging mercury drop electrode/pyrogallol red & $8.3-83 \mathrm{nM}$ & $1.0 \mathrm{nM}$ & 29 \\
\hline voltammetry & hanging mercury drop electrode/pyrocatechol violet & $0.01-1000 \mathrm{nM}$ & $0.005 \mathrm{nM}$ & 30 \\
\hline voltammetry & Cup-SPCE & $52-2000 \mathrm{nM}$ & $26 \mathrm{nM}$ & 31 \\
\hline fluorescence & $N$-butyl alcohol extraction & $0.94-156 \mathrm{nM}$ & $0.94 \mathrm{nM}$ & 28 \\
\hline colorimetry & rhodamine B & $167-12200 \mathrm{nM}$ & $20 \mathrm{nM}$ & 20 \\
\hline colorimetry & solid-phase extraction/phenylhydrazine & $5-125 \mu \mathrm{M}$ & $2.1 \mu \mathrm{M}$ & 32 \\
\hline colorimetry & molybdenum-catalyzed oxidation of ascorbic acid & $5-200 \mathrm{nM}$ & $5 \mathrm{nM}$ & 33 \\
\hline colorimetry & CTAB-stabilized gold nanorods & $3-70 \mathrm{nM}$ & $1 \mathrm{nM}$ & This work \\
\hline
\end{tabular}

including $\mathrm{Li}^{+}, \mathrm{Na}^{+}, \mathrm{K}^{+}, \mathrm{Ca}^{2+}, \mathrm{Mg}^{2+}, \mathrm{Al}^{3+}, \mathrm{Zn}^{2+}, \mathrm{Cu}^{2+}, \mathrm{Fe}^{3+}, \mathrm{Co}^{2+}$, $\mathrm{Ni}^{2+}, \mathrm{Ag}^{+}, \mathrm{Mn}^{2+}, \mathrm{Pb}^{2+}, \mathrm{Hg}^{2+}, \mathrm{Cd}^{2+}, \mathrm{Cr}^{3+}, \mathrm{Cr}(\mathrm{VI}), \mathrm{SO}_{4}{ }^{2-}, \mathrm{PO}_{4}{ }^{3-}$, $\mathrm{CO}_{3}{ }^{2-}$, and $\mathrm{NO}_{3}{ }^{-}, \mathrm{NO}_{2}^{-}$at different concentrations as shown in Figure 5. It was found that the color and maximum

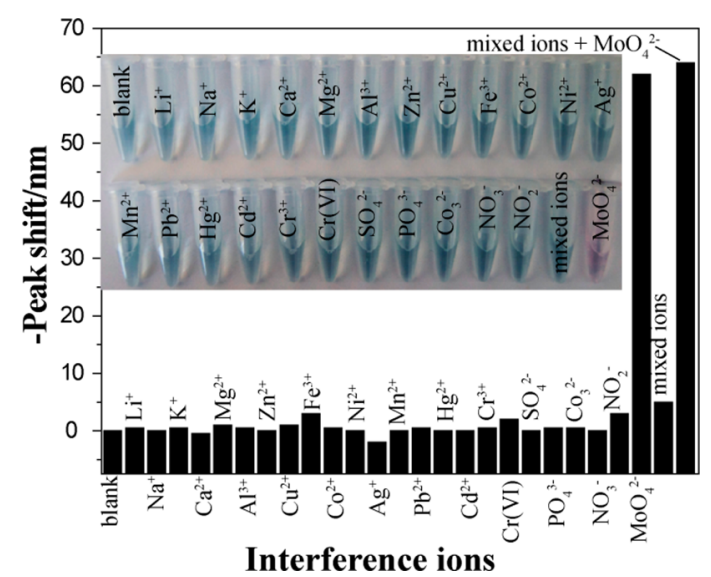

Figure 5. Longitudinal LSPR peak shift of GNRs responding to different ions at concentration of $10 \mu \mathrm{M}$ except for $500 \mathrm{nM}$ for $\mathrm{Fe}^{3+}$, $\mathrm{Cr}(\mathrm{VI})$, and $\mathrm{NO}_{2}{ }^{-}, 1.0 \mu \mathrm{M}$ for $\mathrm{Cd}^{2+}$ and $\mathrm{Ag}^{+}$, and $50 \mathrm{nM}$ for $\mathrm{MoO}_{4}{ }^{2-}$.

absorption wavelength of GNRs changed very little with the addition of those ions. However, the addition of $50 \mathrm{nM}$ $\mathrm{MoO}_{4}{ }^{2-}$ caused the solution color to change from blue to slight red, accompanied by a significant peak shift of $63 \mathrm{~nm}$ in the longitudinal LSPR peak. The interference of other ions on the sensing of $\mathrm{MoO}_{4}{ }^{2-}$ was also evaluated by mixing the ions mentioned above and GNRs in acetate buffer solution in the presence and absence of $\mathrm{MoO}_{4}{ }^{2-}$. The results showed that the presence of those ions had negligible effects on the detection of $\mathrm{MoO}_{4}{ }^{2-}$. Therefore, we concluded that the probe displayed excellent selectivity toward $\mathrm{MoO}_{4}{ }^{2-}$. It should be noted that some of the above ions, including $\mathrm{Co}^{2+}, \mathrm{Cu}^{2+}, \mathrm{Fe}^{3+}, \mathrm{NO}_{2}^{-}$, $\mathrm{Cr}(\mathrm{VI})$, can also be sensed by etching of GNRs, but they can only lead to a slight peak shift even at higher concentration under this condition. Two reasons contribute to the high selectivity toward to $\mathrm{MoO}_{4}{ }^{2-}$. One is the inconsistence of the experimental conditions with other methods. For example, the etching-based detection of $\mathrm{Co}^{2+}$ is conducted under alkaline condition, and the etching-based detection of $\mathrm{Cu}^{2+}, \mathrm{Fe}^{3+}, \mathrm{NO}_{2}{ }^{-}$, and $\mathrm{Cr}(\mathrm{VI})$ requires strong acidic solution (e.g., $1.0 \mathrm{M} \mathrm{HCl}$ ).
The other reason is that only $\mathrm{MoO}_{4}{ }^{2-}$ possesses the peroxidaselike activity that can catalyze the oxidization of iodide by $\mathrm{H}_{2} \mathrm{O}_{2}$ to produce iodine under the $\mathrm{pH} 3.6$, which means molybdate was not consumed in the etching process. The catalysis oxidation process can produce an abundance of etching reagent, iodine, within limited time and therefore improved the sensitivity for sensing of molybdate. The high sensitivity means that a low concentration of molybdate can be detected even in the presence of high concentrations of other ions.

Detection of Molybdate in Real Samples. To test the applicability of the proposed method for molybdate detection, real samples, including drinking water, tap water, and seawater, were tested using this method. To reduce the interference of sample matrix and get more accurate results, the samples were diluted by 10 times. Table 2 showed the detection results using

Table 2. Determination Results in Real Samples by the Proposed Method

\begin{tabular}{cccccr}
\multicolumn{2}{c}{ sample } & $\begin{array}{c}\text { spiked } \\
\text { concentration } \\
(\mathrm{nM})\end{array}$ & $\begin{array}{c}\text { detected } \\
(\mathrm{nM})\end{array}$ & $\begin{array}{c}\text { recovery } \\
(\%)\end{array}$ & $\begin{array}{r}\text { RSD } \\
(\%)\end{array}$ \\
\multirow{2}{*}{$\begin{array}{c}\text { drinking } \\
\text { water }\end{array}$} & sample 1 & 100 & 102.8 & 102.8 & 9.2 \\
& sample 2 & 300 & 305.2 & 101.7 & 5.7 \\
\multirow{3}{*}{ tap water } & sample 3 & 500 & 463.5 & 92.7 & 2.6 \\
& sample 1 & 100 & 93.0 & 93.0 & 13.5 \\
& sample 2 & 300 & 289.7 & 96.6 & 3.3 \\
& sample 3 & 500 & 526.0 & 105.2 & 7.2 \\
sea water & sample 1 & 100 & 81.5 & 81.5 & 8.5 \\
& sample 2 & 200 & 171.8 & 85.9 & 2.7 \\
& sample 3 & 400 & 344.8 & 86.2 & 4.7 \\
\hline
\end{tabular}

the proposed method. The detection results were consistent with the spiked concentrations. This indicates the method could be a promising tool for the rapid on-site monitoring of molybdate.

\section{CONCLUSION}

Here, we have developed a sensitive and selective approach for the visual sensing of molybdate in aqueous media based on enzymatic-like etching of GNRs. As compared to other sensors for the detection of molybdenum, our sensor shows a rapid response $(15 \mathrm{~min})$ and sensitivity toward molybdate, with a detectable range from 3 to $70 \mathrm{nM}$. To the best of our knowledge, the visual detection limit, $10 \mathrm{nM}$, is among the 
lowest reported for the visual detection of molybdate. The excellent visual sensitivity not only avoids sophisticated apparatus but also allows sufficient sample dilution. As compared to traditional nanoparticle-aggregation-based methods, this nanoparticle-etching-based method can avoid false positive results coming from autoaggregation of nanoparticles. Because of these intrinsic merits, the sensor promises to be a practical tool for on-site monitoring of molybdate. In terms of methodology, we consider other targets can also be detected by this strategy if they can selectively mediate the formation of $\mathrm{I}_{2}$ under given conditions. From the perspective of principle, we proposed a mechanism for the triiodine-mediated oxidation of gold, which gives a good supplement to the recent report about tribromide-mediated oxidation of gold nanorods.

\section{ASSOCIATED CONTENT}

\section{S Supporting Information}

The Supporting Information is available free of charge on the ACS Publications website at DOI: 10.1021/acs.langmuir.5b02113.

Figures for the certification of the etching mechanism and the optimization of experimental conditions (PDF)

\section{AUTHOR INFORMATION}

\section{Corresponding Author}

*Fax/phone: 086-535-2109133. E-mail: zhpchen@yic.ac.cn.

\section{Notes}

The authors declare no competing financial interest.

\section{ACKNOWLEDGMENTS}

This research was financially supported by the Department of Science and Technology of Shandong Province (BS2009DX006), the NSFC (no. 21275158), and the project sponsored by SRF for ROCS and the 100 Talents Program of the CAS.

\section{REFERENCES}

(1) Deng, J.; Yu, P.; Wang, Y.; Yang, L.; Mao, L. Visualization and quantification of neurochemicals with gold nanoparticles: opportunities and challenges. Adv. Mater. 2014, 26 (40), 6933-43.

(2) Du, J.; Zhu, B.; Peng, X.; Chen, X. Optical reading of contaminants in aqueous media based on gold nanoparticles. Small 2014, 10 (17), 3461-79.

(3) Liu, D.; Wang, Z.; Jiang, X. Gold nanoparticles for the colorimetric and fluorescent detection of ions and small organic molecules. Nanoscale 2011, 3 (4), 1421-33.

(4) Saha, K.; Agasti, S. S.; Kim, C.; Li, X.; Rotello, V. M. Gold nanoparticles in chemical and biological sensing. Chem. Rev. 2012, 112 (5), 2739-79.

(5) Saa, L.; Coronado-Puchau, M.; Pavlov, V.; Liz-Marzan, L. M. Enzymatic etching of gold nanorods by horseradish peroxidase and application to blood glucose detection. Nanoscale 2014, 6 (13), 74059.

(6) Xia, Y.; Ye, J.; Tan, K.; Wang, J.; Yang, G. Colorimetric visualization of glucose at the submicromole level in serum by a homogenous silver nanoprism-glucose oxidase system. Anal. Chem. 2013, 85 (13), 6241-7.

(7) Chen, Z. P.; Liu, R. L.; Wang, S. S.; Qu, C. L.; Chen, L. X.; Wang, Z. Colorimetric sensing of copper(II) based on catalytic etching of gold nanorods. RSC Adv. 2013, 3 (32), 13318-13323.

(8) Liu, R.; Chen, Z.; Wang, S.; Qu, C.; Chen, L.; Wang, Z. Colorimetric sensing of copper(II) based on catalytic etching of gold nanoparticles. Talanta 2013, 112, 37-42.
(9) Zhang, Z.; Chen, Z.; Qu, C.; Chen, L. Highly Sensitive Visual Detection of Copper ions Based on the Shape-dependent LSPR Spectroscopy of Gold Nanorods. Langmuir 2014, 30 (12), 36253630.

(10) Li, F.-M.; Liu, J.-M.; Wang, X.-X.; Lin, L.-P.; Cai, W.-L.; Lin, X.; Zeng, Y.-N.; Li, Z.-M.; Lin, S.-Q. Non-aggregation Based Label Free Colorimetric Sensor for the Detection of Cr (VI) Based on Selective Etching of Gold Nanorods. Sens. Actuators, B 2011, 155 (2), 817-822.

(11) Liu, J. M.; Jiao, L.; Cui, M. L.; Lin, L. P.; Wang, X. X.; Zheng, Z. Y.; Zhang, L. H.; Jiang, S. L. Highly sensitive non-aggregation colorimetric sensor for the determination of I- based on its catalytic effect on Fe3+ etching gold nanorods. Sens. Actuators, B 2013, 188, 644-650.

(12) Chen, Z.; Zhang, Z.; Qu, C.; Pan, D.; Chen, L. Highly sensitive label-free colorimetric sensing of nitrite based on etching of gold nanorods. Analyst 2012, 137 (22), 5197-200.

(13) Zou, R. X.; Guo, X.; Yang, J.; Li, D. D.; Peng, F.; Zhang, L.; Wang, H. J.; Yu, H. Selective etching of gold nanorods by ferric chloride at room temperature. CrystEngComm 2009, 11 (12), 27972803.

(14) Chen, Y. Y.; Chang, H. T.; Shiang, Y. C.; Hung, Y. L.; Chiang, C. K.; Huang, C. C. Colorimetric assay for lead ions based on the Leaching of gold nanoparticles. Anal. Chem. 2009, 81 (22), 9433-9.

(15) Ferhan, A. R.; Guo, L.; Zhou, X.; Chen, P.; Hong, S.; Kim, D. H. Solid-phase colorimetric sensor based on gold nanoparticle-loaded polymer brushes: lead detection as a case study. Anal. Chem. 2013, 85 (8), 4094-9.

(16) Lee, Y. F.; Huang, C. C. Colorimetric assay of lead ions in biological samples using a nanogold-based membrane. ACS Appl. Mater. Interfaces 2011, 3 (7), 2747-54.

(17) Shang, L.; Jin, L.; Dong, S. Sensitive turn-on fluorescent detection of cyanide based on the dissolution of fluorophore functionalized gold nanoparticles. Chem. Commun. 2009, 21, 3077-9.

(18) Tripathy, S. K.; Woo, J. Y.; Han, C. S. Highly selective colorimetric detection of hydrochloric acid using unlabeled gold nanoparticles and an oxidizing agent. Anal. Chem. 2011, 83 (24), 9206-12.

(19) Zhang, Z.; Chen, Z.; Pan, D.; Chen, L. Fenton-like reactionmediated etching of gold nanorods for visual detection of $\mathrm{Co}(2+)$. Langmuir 2015, 31 (1), 643-50.

(20) Tavallali, H.; Deilamy-Rad, G.; Parhami, A.; Hasanli, N. An efficient and ultrasensitive rhodamine B-based reversible colorimetric chemosensor for naked-eye recognition of molybdenum and citrate ions in aqueous solution: sensing behavior and logic operation. Spectrochim. Acta, Part A 2015, 139, 253-61.

(21) Mansouri, A. I.; Afzali, D.; Ganjavi, F. Dispersive liquid-liquid microextraction of trace amounts of molybdenum prior to electrothermal atomic absorption spectrometry determination. Int. J. Environ. Anal. Chem. 2014, 94 (3), 247-254.

(22) Shamsipur, M.; Habibollahi, S. A highly sensitive procedure for determination of ultra trace amounts of molybdenum by graphite furnace atomic absorption spectrometry after dispersive liquid-liquid microextraction. Microchim. Acta 2010, 171 (3-4), 267-273.

(23) Huang, C. Y.; Lee, N. M.; Lin, S. Y.; Liu, C. Y. Determination of vanadium, molybdenum and tungsten in complex matrix samples by chelation ion chromatography and on-line detection with inductively coupled plasma mass spectrometry. Anal. Chim. Acta 2002, 466 (1), $161-174$.

(24) Luong, E. T.; Houk, R. S.; Serfass, R. E. Chromatographic isolation of molybdenum from human blood plasma and determination by inductively coupled plasma mass spectrometry with isotope dilution. J. Anal. At. Spectrom. 1997, 12 (7), 703-708.

(25) Capitan, F.; Sanchezpalencia, G.; Navalon, A.; Capitanvallvey, L. F.; Vilchez, J. L. Simultaneous determination of molybdenum and tungsten by 1st-derivative synchronous solid-phase spectrofluorometry. Anal. Chim. Acta 1992, 259 (2), 345-353.

(26) Phansi, P.; Henriquez, C.; Palacio, E.; Nacapricha, D.; Cerda, V. Automated in-chip kinetic-catalytic method for molybdenum determination. Talanta 2014, 119, 68-74. 
(27) Pelit, L.; Kocak, S.; Pelit, F. O.; Turkmen, H.; Ertas, F. N. A spectrophotometric method for determination of molybdenum in water samples by using pyrogallol red and a water soluble ionic liquid. Anal. Methods 2013, 5 (20), 5792-5798.

(28) Liao, C. D.; Geng, G. X.; Lu, J. P.; Tang, Y. K. Indirect determination of molybdenum in tea with N-butyl Alcohol extraction by atomic fluorescence spectrometry. Fenxi Ниахиe 2013, 40 (6), 964-967.

(29) Ensafi, A. A.; Khayamian, T.; Khaloo, S. S. Application of adsorptive cathodic differential pulse stripping method for simultaneous determination of copper and molybdenum using pyrogallol red. Anal. Chim. Acta 2004, 505 (2), 201-207.

(30) Zarei, K.; Atabati, M.; Ilkhani, H. Catalytic adsorptive stripping voltammetry determination of ultra trace amount of molybdenum using factorial design for optimization. Talanta 2006, 69 (4), 816-21.

(31) Sadeghi, S.; Garmroodi, A. Design and construction of a new modified screen-printed sensor for voltammetric determination of molybdenum(VI) ions. Electroanalysis 2013, 25 (1), 323-330.

(32) Filik, H.; Aksu, D.; Apak, R.; Boz, I. Rapid sensing of molybdenum by combined colorimetric solid-phase extractionReflectance spectroscopy. Sens. Actuators, B 2009, 141 (2), 491-497.

(33) Kawakubo, S.; Ogihara, K.; Watanabe, M.; Iwatsuki, M. Field determination of trace molybdenum in river-water samples by a visual catalytic method. Field Anal. Chem. Technol. 1999, 3 (1), 29-35.

(34) Sau, T. K.; Murphy, C. J. Seeded high yield synthesis of short Au nanorods in aqueous solution. Langmuir 2004, 20 (15), 6414-20.

(35) Kalayci, S.; Somer, G.; Ekmekci, G. Preparation and application of a new glucose sensor based on iodide ion selective electrode. Talanta 2005, 65 (1), 87-91.

(36) Copper, C. L.; Koubek, E. Kinetics of the molybdate and tungstate catalyzed oxidation of iodide by hydrogen peroxide. Inorg. Chim. Acta 1999, 288 (2), 229-232.

(37) Chen, H.; Shao, L.; Li, Q.; Wang, J. Gold nanorods and their plasmonic properties. Chem. Soc. Rev. 2013, 42 (7), 2679-2724.

(38) Kou, X.; Ni, W.; Tsung, C. K.; Chan, K.; Lin, H. Q.; Stucky, G. D.; Wang, J. Growth of gold bipyramids with improved yield and their curvature-directed oxidation. Small 2007, 3 (12), 2103-13.

(39) Tsung, C. K.; Kou, X.; Shi, Q.; Zhang, J.; Yeung, M. H.; Wang, J.; Stucky, G. D. Selective shortening of single-crystalline gold nanorods by mild oxidation. J. Am. Chem. Soc. 2006, 128 (16), $5352-3$.

(40) Zhu, Q.; Wu, J.; Zhao, J.; Ni, W. Role of Bromide in Hydrogen Peroxide Oxidation of CTAB-Stabilized Gold Nanorods in Aqueous Solutions. Langmuir 2015, 31 (14), 4072-4077.

(41) Ni, W.; Kou, X.; Yang, Z.; Wang, J. Tailoring longitudinal surface plasmon wavelengths, scattering and absorption cross sections of gold nanorods. ACS Nano 2008, 2 (4), 677-86.

(42) Hicks, M.; Gebicki, J. M. A spectrophotometric method for the determination of lipid hydroperoxides. Anal. Biochem. 1979, 99 (2), 249-253.

(43) Davis, A.; Tran, T.; Young, D. R. Solution chemistry of iodide leaching of Gold. Hydrometallurgy 1993, 32 (2), 143-159.

(44) Rodriguez-Fernandez, J.; Perez-Juste, J.; Mulvaney, P.; LizMarzan, L. M. Spatially-directed oxidation of gold nanoparticles by $\mathrm{Au}(\mathrm{III})$-CTAB complexes. J. Phys. Chem. B 2005, 109 (30), 14257-61.

(45) Yu, H.; Zi, F. T.; Hu, X. Z.; Zhong, J.; Nie, Y. H.; Xiang, P. Z. The copper-ethanediamine-thiosulphate leaching of gold ore containing limonite with cetyltrimethyl ammonium bromide as the synergist. Hydrometallurgy 2014, 150, 178-183.

(46) Elding, L.; Groning, A. Kinetics, mechanism and equilibria for halide substitution processes of chloro bromo complexes of gold (III). Acta Chem. Scand. 1978, 32 (9), 867-877.

(47) Anandhakumar, S.; Rajaram, R.; Mathiyarasu, J. Unusual seedless approach to gold nanoparticle synthesis: application to selective rapid naked eye detection of mercury (II). Analyst 2014, 139 (13), 3356-3359.

(48) Elding, L.; Olsson, L. Kinetics and mechanism for reduction of tetrachloro-and tetrabromoaurate (III) by iodide. Inorg. Chem. 1982, 21 (2), 779-784. 